\title{
Editorial
}

\section{To Those Who Dedicate Their Lives}

A few hours ago I learned of the untimely death of a colleague. Taku Frank Nimura, librarian, had devoted twenty-five years of his professional life to both the academic community and the library staff at California State University, Sacramento. During these years, how many thank-yous were given, how many notes of appreciation were written? Too few I would imagine.

Daily, library managers practice their craft: to plan, direct, and control. This standard litany of the managerial role is repeated endlessly during schooling and afterwards. We model ourselves accordingly, and we impose it on the supervised. Lately I have paused to reflect and to wonder about the values implicit in standard practice. Today, I am confronted with the problem more directly. What human qualities did I convey to Taku? We are told to balance tasks and people. We all know the inequality of this balance.

Years ago I told my supervisor about a good job performed by a staff member. I felt it deserved a written note of thanks. "No, it will just come back to me in his professional file," was the response. Is it true that a good job acknowledged is only a piece of ammunition? Have some of us constricted our humanity in the service of a role that fosters a selfimposed form of alienation?

Some of us go to conferences frequently. Some of us spend significant blocks of time away from the trenches. We reinforce our behavior with talk of well-rounded professionalism, and we seek to develop a reputation that allows us to meet the scrutiny of those who are to conduct a personnel review for retention, tenure, and promotion. In the process, we sometimes exaggerate the validity of one path over the paths chosen by others. As professionals, we sometimes build structures that exclude others, thereby diminishing their contributions.

In The Leader: A New Face for American Management, Michael Maccoby offers a new goal for managers: to bring out the best in people. Whether as managers or professionals, we should pursue this goal. We should seek to honor the labor of all staff. We should find ways to extend, on a daily basis, our sense of appreciation. Long hours and long years of service pass with scant notice. This service may have its own rewards, but they are marginal in comparison to what has been offered. We need to find more appropriate ways to thank those who dedicate their lives.

CHARLES R. MARTELL 